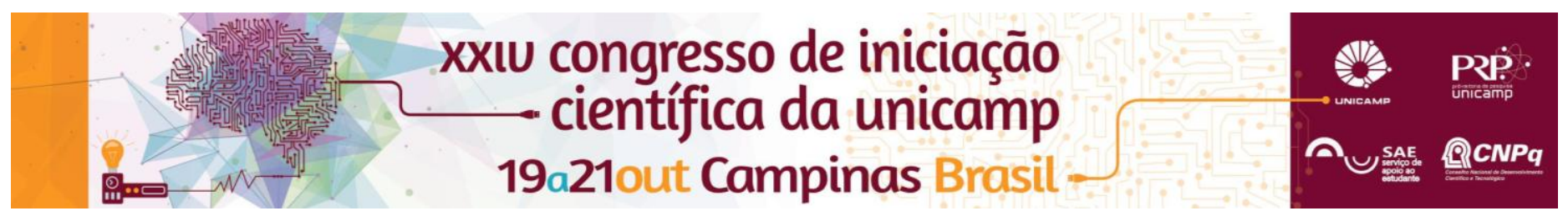

\title{
Observatório Permanente de Conflitos Urbanos de Campinas-SP: uma análise a partir da região do Jardim Campo Belo.
}

\section{Maurício Moysés (IC), Adriana Maria Bernardes (PQ)}

\begin{abstract}
Resumo
A pesquisa teve como objetivo inventariar os conflitos urbanos (VAINER, 2005) em Campinas-SP com ênfase na região do Jardim Campo Belo, no entorno do Aeroporto Internacional de Viracopos. As atividades vêm sendo desenvolvidas desde agosto/2013, através de revisões bibliográficas, levantamento de dados em meios difusores de informações (jornais impressos; online; TV) e a partir de entrevistas com o poder público e a sociedade civil.
\end{abstract}

Palavras-chave: urbanização corporativa, conflitos urbano, Campinas-SP.

\section{Introdução}

A pesquisa é uma renovação da Iniciação Científica de 2014, e vem sendo desenvolvida desde agosto de 2013, vinculado ao projeto "Implantação do Observatório Permanente de Conflitos Urbanos de Campinas-SP", em curso no GEOPLAN/IG/UNICAMP, sob coordenação da Profa. Dra. Adriana Bernardes. Essa iniciativa, por sua vez, toma parte da rede nacional de Observatórios Permanentes de Conflitos Urbanos, sediada no ETTERN/IPPUR/UFRJ, sob coordenação do Prof. Dr. Carlos Vainer. O objetivo foi identificar a espessura dos conflitos urbanos ocorridos em 2015 em Campinas-SP.

\section{Resultados e Discussão}

A dinâmica das cidades brasileiras, e nesse caso da cidade de Campinas-SP, nos revela que as intervenções por parte do poder público na produção do espaço urbano são crescentemente seletivas. O planejamento e gestão das cidades conduzem, portanto, a difusão seletiva do que meio técnico-científicoinformacional (SANTOS, 1993) no território, fazendo com que esse movimento resulte em requalificação de determinados lugares e abandono de outros.

O funcionamento de Campinas-SP passa a ser regido de forma hierárquica e seletiva, de modo que os objetos técnicos são distribuídos profundamente de forma desigual. Criam-se espaços luminosos e espaços opacos que concretizam o modo de urbanização corporativo (SANTOS, 1993).

Para compreendermos a dinâmica atual de Campinas-SP e adentrarmos na região do Jardim Campo Belo a partir dos conflitos urbanos, devemos tomá-los como uma chave que nos dá indícios das relações sociais existentes no espaço urbano e a expressão de sua conflituosidade.

Em 2015 foram registrados 74 conflitos pelo Observatório Permanente de Conflitos Urbanos de Campinas-SP; o Centro da cidade se destaca como a "localização/área de abrangência" de maior frequência, com 10 conflitos urbanos registrados.

$\mathrm{Na}$ região do Jardim Campo Belo foram registrados 2 conflitos urbanos, ambos referentes ao "Objeto" Transito, Transporte e circulação, tendo o Governo Municipal como agente reclamado e as ações foram motivadas pelos Moradores nas duas ocasiões. Somente um dos conflitos foi noticiado nos meios de comunicação por nós analisados, fato que reforça a constatação de que a difusão de noticias por esse meio DOI: 10.19146/pibic-2016-51726 privilegia as regiões centrais da cidade. $\mathrm{O}$ outro conflito urbano foi registrado a partir de trabalho de campo realizado na região em março de 2015, comunicado pelo líder da Associação de Moradores do bairro Campituba 1.

\section{Conclusões}

O trabalho permitiu pensar os distintos usos do território e analisar os conflitos que eclodem no cotidiano da Campinas-SP e na região do Jardim Campo Belo. Preocupa-nos compreender o espaço geográfico aporte de todos os agentes e organizações, revelando relações contraditórias e espontâneas que definem as transformações políticas e sociais da realidade urbana e principalmente dos lugares.

Portanto, temos a partir da análise dos conflitos urbanos uma possibilidade de leitura da cidade e que expressam as marcas impostas pelas normas hegemônicas no território. A partir do levantamento e das análises de dados, é possível torná-lo um instrumento social de ação não-hegemônica que contribua para elaborar outros tipos de planejamento urbano e explicite as reais condições de vida nas cidades.

\section{Agradecimentos}

Agradeço ao $\mathrm{CNPq}$ pelo financiamento da pesquisa, a Prof ${ }^{\underline{a}} \operatorname{Dr}^{\mathrm{a}}$ Adriana Maria Bernardes pelo apoio e orientação, e a equipe do Observatório Permanente de Conflitos Urbanos de Campinas-SP.

SANTOS, Milton. A urbanização brasileira. São Paulo: Edusp, 1993.

SILVA, Adriana M. B. Implantação do observatório dos conflitos urbanos de campinas-SP. Projeto. GEOPLAN, Instituto de Geociências, Universidade Estadual de Campinas, 2013.

VAINER, Carlos. Núcleo Experimental de Planejamento Conflitual. Projeto. IPPUR, Instituto de Geociências, Universidade Federal do Rio de Janeiro, 2005. 